Tersedia online di:http://ejournal-balitbang.kkp.go.id/index.php/jkpi
e-mail:jkpi.puslitbangkan@gmail.com
JURNAL KEBIJAKANPERIKANANINDONESIA
Volume 10 Nomor 1 Mei 2018
p-ISSN: 1979-6366
e-ISSN: 2502-6550
Nomor Akreditasi Kementerian RISTEKDIKTI: 21/E/KPT/2018

\title{
KESIAPAN DAN PENGUATAN KELEMBAGAAN MASYARAKAT DALAM MENDUKUNG PENGELOLAAN PROGRAM RESTOCKING LOBSTER
}

\section{READINESS AND STRENGTHENING OF COMMUNITY INSTITUTIONS IN ORDER TO SUPPORT RESTOCKING LOBSTER MANAGEMENT POLICY}

\author{
Zahri Nasution ${ }^{\star 1}$, Bayu Vita Indah' ${ }^{1}$ Yanti dan Nurlaili' \\ 'Balai Besar Riset Sosial Ekonomi Kelautan dan Perikanan, Jln. Pasir Putih I, Ancol Timur, Jakarta Utara-14430, Indonesia \\ Teregistrasi I tanggal: 23 Oktober 2017; Diterima setelah perbaikan tanggal: 16 Maret 2018; \\ Disetujui terbit tanggal: 07 Mei 2018
}

\begin{abstract}
ABSTRAK
Pemulihan populasi lobster dilihat dari aspek sosial ekonomi adalah penyiapan rekayasa sosial dalam mendukung upaya penguatan kelembagaan restocking lobster berbasis masyarakat. Penelitian ini bertujuan untuk mengevaluasi kesiapan dan penguatan kelembagaan masyarakat dalam pengelolaan program restocking lobster untuk meningkatkan kesejahteraan masyarakat. Penelitian dilakukan pada tahun 2015 di Nusa Tenggara Barat (Kab. Lombok Tengah dan Kab. Lombok Timur), Jawa Barat (Kab. Pangandaran) dan Banten (Kab. Pandeglang). Data aspek kelembagaan yang dikumpulkan adalah kegiatan pemanfaatan dan pengelolaan sumberdaya perikanan kaitannya dengan pengembangan restocking lobster. Informan terdiri dari masyarakat nelayan, petugas pemerintah daerah di berbagai kantor dinas terkait, petugas di kantor Desa, dan informan yang dianggap mengetahui keberadaan data dan informasi kelembagaan pengelolaan sumberdaya perikanan di wilayah yang diteliti. Wawancara dilakukan secara terstruktur dan tidak terstruktur yang dipandu dengan topik data. Data dianalisis menggunakan metode kualitatif. Hasil kajian menunjukkan bahwa lokasi yang paling memiliki kesiapan dalam mendukung program restocking lobster adalah Kabupaten Pangandaran. Opsi kebijakan yang diperlukan dalam rangka meningkatkan kinerja program restocking lobster berbasis masyarakat adalah memberikan pemahaman kepada pengurus organisasi yang terbentuk dalam program restocking lobster dan manfaatnya bagi masyarakat, sumber daya dan populasi lobster dan pemerintah; termasuk didalamnya regulasi penangkapan dan dukungan sarana dan prasarana untuk kelancaran petugas pengawasan di lapangan. Penegakan aturan terkait dengan penetapan otoritas pengelolaan sumberdaya lobster terkait program restocking lobster perlu dilakukan.
\end{abstract}

Kata Kunci: Kelembagaan; restocking; lobster; berbasis masyarakat

\begin{abstract}
Lobster population recovery, viewed from the social and economic aspects will require the preparation of social engineering in support of the efforts to strengthen community-based lobster restocking. This study was conducted to evaluatereadiness and institutional strengthening of in the community in the management of lobster restocking program, with the ultimate goal is to improve the welfare of society. The study was conducted in 2015 with the location of West Nusa Tenggara (in Central Lombok district and East Lombok), West Java (in Pangandaran district), and Banten (in the Pandeglang district). The data collected related to the institutional aspects is the activity of resource utilization and management of fisheries in connection with the development of restocking activities. Informants consisted of fishing communities, local government officials in the various offices concerned, the clerk in the office of the chief, and informants were considered to know the existence of data and information on fisheries resources management institutions in the regions studied. Interviews were conducted either in a structured or unstructured guided by the topic of data prepared in this study. Data were analyzed using qualitative methods. The results showed that most locations
\end{abstract}


have the readiness to support the restocking program is Pangandaran Regency. In order to improve the performance of community-based lobster restocking programs, the policy options required are to provide an understanding to the organizational board formed in the lobster restocking program and its benefits to communities, resources and government. Including the restrictions on the use of fishing gear and support facilities and infrastructure that provide fluency in the duty as a supervisory officer in the field. It is also necessary to enforce the rules related to the establishment of fish / lobster resource management authority related to the lobster restocking program.

\section{Keywords: Institution; restocking; lobster; community based}

\section{PENDAHULUAN}

Lobster atau udang karang merupakan komoditas perikanan yang potensial dan bernilai ekonomis penting yang permintaannya terus meningkat baik untuk pasar domestik maupun ekspor (Setyono, 2006). Beberapa akibatnya antara lain banyak juvenil lobster yang belum layak jual (kurang dari 100 gram) turut tertangkap, sehingga dikhawatirkan akan mengganggu proses rekruitmen alami lobster tersebut (Fauzi et al., 2013). Disamping itu, sumberdaya benih alam memegang peranan penting juga pada kegiatan budidaya yang masih tergantung terhadap keberadaan pasokan benih alam (Mallawa, 2006; Suastika et al., 2008). Begitu juga untuk keberlangsungan dan keberlanjutan program penebaran kembali komoditas tertentu yang ada di perairan Inonesia.

Benih Lobster merupakan salah satu jenis komoditas yang banyak dieksploitasi di Indonesia terutama pada akhir tahun dan awal tahun berikutnya yaitu sekitar bulan November hingga Januari (Suastika et al., 2008; Aisyah et al., 2009). Bahkan pada beberapa tahun yang lalu (sejak 2011 hingga 2014) benih Lobster merupakan salah satu komoditas unggulan ekspor hasil perikanan dan kelautan Indonesia. Hingga saat ini, nelayan Indonesia di berbagai wilayah penangkapan masih bergantung dengan usaha penangkapan benih lobster dari alam bebas, sehingga diperkirakan dapat menyebabkan menurunnya ketersediaan populasi dan mengecilnya ukuran lobster di perairan pantai seperti di selatan Jawa, khususnya di wilayah perairan Kabupaten Gunung Kidul dan Kabupaten Pacitan (Hargiyatno et al., 2013). Dalam rangka menjaga kelestarian poulasi lobster dalam jangka panjang di perairan NTB diperlukan pengaturan tentang pembatasan aktivitas penangkapan benih (Erlania et al., 2016).

Berkaitan dengan pengaturan penangkapan benih lobster ini, Kementerian Kelautan dan Perikanan (KKP) pada awal tahun 2015 mengeluarkan Peraturan Menteri No.1/Permen KP/2015 Tentang Penangkapan Lobster (Panulirus spp), Kepiting (Scylla spp), dan Rajungan (Portunus pelagicus spp) (KKP, 2015a). Beberapa larangan yang terkandung dalam peraturan tersebut antara lain melarang penangkapan lobster dalam kondisi bertelur (pasal 2) dan melarang menangkap lobster yang berukuran lebih kecil atau dengan ukuran $8 \mathrm{~cm}$ (pasal 3) (KKP, 2015a). Peraturan menteri tersebut dilengkapi dengan Surat Edaran Menteri Kelautan dan Perikanan No.18/Men KP/2015 tanggal 20 Januari 2015 Tentang Penangkapan Lobster (Panulirus spp), Kepiting (Scylla spp), dan Rajungan (Portunus pelagicus spp) (KKP, 2015b). Dalam surat edaran tersebut dikemukakan ukuran lobster yang boleh ditangkap dan diperjualbelikan adalah dengan ukuran lebih dari 200 gram (periode Januari 2015 hingga Desember 2015), sedangkan pada periode mulai Januari 2016 dan seterusnya hanya diperbolehkan untuk ukuran yang panjang karapasnya lebih dari $8 \mathrm{~cm}$ atau ukuran berat lebih dari $300 \mathrm{gram}$ (KKP. 2015b).

Dalam rangka menunjang usaha pelestarian sumberdaya lobster di Indonesia dilakukan berbagai kegiatan penelitian yang bertujuan untuk memulihkan populasi lobster. Pemulihan populasi tersebut melalui pengelolaan sumberdaya lobster dengan basis pemulihan stok (stock enchancement) dan konservasi sumberdaya lobster dengan penebaran ulang (restocking). Kegiatan pemulihan populasi lobster merupakan salah satu bagian dari sistem manajemen yang mengintegrasikan antara kegiatan penelitian terkait perikanan budidaya, perikanan tangkap, teknologi kelautan, dan sosial ekonomi kelautan dan perikanan.

Salah satu rangkaian kegiatan pemulihan populasi lobster yang dilakukan adalah dengan melakukan kegiatan penelitian terkoordinasi antar satuan kerja penelitian. Satuan kerja penelitian terkait perikanan budidaya, perikanan tangkap, dan teknologi kelautan berperan pada penyiapan teknis untuk benih lobster yang akan dipulihkan, mulai dari penyediaan, pemeliharaan benih (intermediate culture) hingga ukuran siap tebar, penyesuaian dengan lingkungan perairan, penebaran benih ke laut, hingga suatu saat ditangkap kembali. Di lain pihak, peran dari satuan kerja penelitian sosial ekonomi kelautan dan perikanan lebih terkait pada penyiapan rekayasa sosial dalam rangka mengetahui kesiapan kelembagaan dan 
penguatan kelembagaan restocking lobster berbasis masyarakat. Kelembagaan dalam program restocking seperti ini dapat bermakna sebagai aturan main dan organisasi yang mampu melaksanakan program tersebut (Kolopaking, 1998).

Kelembagaan sebagai aturan main adalah perlunya pembentukan aturan dalam mengelola sumberdaya lobster tersebut, sedangkan kelembagaan dalam arti organisasi harus ada organisasi pengelola yang membuat aturan, menjalankan aturan, berfungsi sebagai pengawas pelaksanaan aturan, dan penindakan serta pemberian hukuman atau sanksi. Dengan demikian diharapkan lobster merupakan salah satu bagian dari sumber daya alam Indonesia, yang dapat dikelola dan dimanfaatkan secara lestari dan berkelanjutan untuk tujuan peningkatan kesejahteraan masyarakat, baik saat ini maupun di masa mendatang. Penelitian ini bertujuan untuk mengetahui kesiapan kelembagaan yang terdapat di masyarakat dalam kerangka pengelolaan program restocking lobster. Dalam kebijakan publik hal tersebut didefinisikan sebagai whatever governments chooses to do or not to do (Dye, 2005; Subarsono, 2006) yaitu pilihan yang ditentukan oleh pemerintah untuk dilakukan oleh para pemangku kepentingan.

Kelembagaan terdapat dalam setiap kehidupan masyarakat, baik pada masyarakat yang masih tradisional ataupun masyarakat modern (Israel, 1987; Soekanto, 2003). Kelembagaan dapat diartikan sebagai suatu sistem tata kelakuan dan hubungan yang berkaitan dengan aktivitas manusia untuk memenuhi kebutuhan khusus dalam kehidupan masyarakat (Martin, 1971; Koentjaraningrat, 1997). Sistem tata kelakuan ini diwujudkan dalam sejumlah peranan dan sistem nilai yang mengatur hubungan antar manusia dengan prinsip adanya tanggung jawab (kewajiban) yang diimbangi dengan hak-hak (Schmid, 1972), serta aturan main yang diperlukan dalam suatu koordinasi kelembagaan (Braun \& Feldbrugge, 1998).
Terkait dengan keberadaan program restocking, maka keberadaan kelembagaan diharapkan dapat memenuhi tujuan akhir yang ingin dicapai yaitu meningkatkan kesejahteraan masyarakat sekitar perairan yang dikelola melalui keterpaduan tiga komponen kegiatan utama. Tiga komponen utama tersebut adalah restocking (pengkayaan stok melalui penebaran kembali jenis ikan tertentu), pemberdayaan unit pembenihan, dan pemberdayaan masyarakat sekitar perairan terutama masyarakat nelayan (DJPB, 2003).

Pada kelembagaan nelayan umumnya dapat bersifat multi fungsi dan terdiri atas struktur organisasi yang disesuaikan dengan kebutuhan masyarakat nelayan (Nasution, 2012). Dalam struktur organisasi nelayan dapat terdiri atas sekretaris, bendahara, dan bidang-bidang yang berfungsi sebagai sarana pelayanan bagi masyarakat pemanfaat terutama masyarakat nelayan (Nasution, 2013).

Analisis data kualitatif merupakan penelusuran terhadap pernyataan-pernyataan umum tentang hubungan antar berbagai kategori data yang berasal dari data yang tersedia (Marshall \& Rossman, 1989; Patton 1990; Moleong, 2004).

\section{BAHASAN \\ KESIAPAN KELEMBAGAAN MASYARAKAT}

Hasil penilaian kondisi faktor-faktor penyusun indikator kelembagaan masyarakat dalam pengelolaan program restocking lobster pada keseluruhan lokasi penelitian dikemukakan pada Tabel 1 hingga 4. Berdasarkan Tabel tersebut dapat dikemukakan bahwa lokasi yang paling memiliki kesiapan dalam mendukung program restocking adalah Kabupaten Pangandaran. Hal ini sesuai dengan kondisi lapangan di wilayah masing-masing yang kesiapan kelembagaannya terlihat sudah memiliki fungsi dan peran dalam kaitannya dengan pemanfaatan dan pengelolaan sumberdaya perikanan. 
Tabel 1. Hasil skoring indikator kelembagaan terkait dengan identifikasi kelembagaan dalam mendukung pengelolaan program restocking lobster.

Table 1. Scoring results of institutional indicators related to institutional identification in support of lobster restocking program management.

\begin{tabular}{|c|c|c|c|c|c|c|c|c|}
\hline $\begin{array}{l}\text { Unsur Penilai } \\
\text { Identifikasi }\end{array}$ & aian Kelembaga & $\begin{array}{r}\operatorname{aan} \& \& \\
N\end{array}$ & $\begin{array}{l}\text { Peraturan / Ins } \\
\text { TB }\end{array}$ & st & $\begin{array}{c}\text { nal \& Regulatory } \\
\text { Jawa Barat }\end{array}$ & & $\begin{array}{c}\text { ssment Eleme } \\
\text { Banten }\end{array}$ & its \\
\hline $\begin{array}{c}\text { Kelembagaan/ } \\
\text { Institutional } \\
\text { Identification }\end{array}$ & $\begin{array}{c}\text { Lombok } \\
\text { Tengah }\end{array}$ & Skor & $\begin{array}{c}\text { Lombok } \\
\text { Timur }\end{array}$ & Skor & Pangandaran & Skor & r Pandeglang & Skor \\
\hline $\begin{array}{l}\text { Kelembagaan } \\
\text { Eksisting/ } \\
\text { existing } \\
\text { Institution }\end{array}$ & $\begin{array}{l}\text { ada } \\
\text { kelembagaan } \\
\text { awik-awik dan } \\
\text { pokmaswas }\end{array}$ & 3 & $\begin{array}{l}\text { ada } \\
\text { kelembagaan } \\
\text { awik-awik dan } \\
\text { pokmaswas }\end{array}$ & 3 & $\begin{array}{l}\text { ada kelembagaan } \\
\text { pokmaswas yg } \\
\text { berfungsi }\end{array}$ & 3 & $\begin{array}{l}\text { ada } \\
\text { kelembagaan } \\
\text { pokmaswas, } \\
\text { tapi belum } \\
\text { berfungsi }\end{array}$ & 2 \\
\hline $\begin{array}{l}\text { Peran } \\
\text { Kelembagaan } \\
\text { Eksisting/ The } \\
\text { role of of } \\
\text { existing } \\
\text { institution }\end{array}$ & $\begin{array}{l}\text { terdapat } \\
\text { kelembagaan } \\
\text { awik-awik dan } \\
\text { pokmaswas } \\
\text { eberfungsi } \\
\text { fdengan baik } \\
\text { dalam } \\
\text { menjalankan } \\
\text { pengelolaan } \\
\text { SDKP }\end{array}$ & 3 & $\begin{array}{l}\text { terdapat } \\
\text { kelembagaan } \\
\text { awik-awik dan } \\
\text { pokmaswas } \\
\text { berfungsi } \\
\text { dengan baik } \\
\text { dalam } \\
\text { menjalankan } \\
\text { pengelolaan } \\
\text { SDKP }\end{array}$ & 3 & $\begin{array}{l}\text { terdapat } \\
\text { kelembagaan } \\
\text { pokmaswas, rukun } \\
\text { nelayan yang } \\
\text { berperan aktif } \\
\text { dalam menjalankan } \\
\text { pengelolaan SDKP }\end{array}$ & 3 & $\begin{array}{l}\text { meski terdapat } \\
\text { kelembagaan } \\
\text { pokmaswas, } \\
\text { belum } \\
\text { berfungsi } \\
\text { dengan baik }\end{array}$ & 2 \\
\hline $\begin{array}{l}\text { Fungsi } \\
\text { Kelembagaan } \\
\text { Eksisting/ } \\
\text { Function of } \\
\text { existing } \\
\text { instituion } \\
\text { Peran \& } \\
\text { Fungsi } \\
\text { Kelembagaan } \\
\text { dalam }\end{array}$ & $\begin{array}{l}\text { hanya } \\
\text { menjalankan } \\
\text { fungsi } \\
\text { eksisting }\end{array}$ & 2 & $\begin{array}{l}\text { hanya } \\
\text { menjalankan } \\
\text { fungsi } \\
\text { eksisting }\end{array}$ & 2 & $\begin{array}{l}\text { kelembagaan } \\
\text { eksisting } \\
\text { menjalankan fungsi } \\
\text { pengawasan, } \\
\text { pembinaan\&sumber } \\
\text { PAD }\end{array}$ & 3 & $\begin{array}{l}\text { kelembagaan } \\
\text { eksisting } \\
\text { belum } \\
\text { menjalankan } \\
\text { fungsi }\end{array}$ & 1 \\
\hline $\begin{array}{l}\text { Mengatasi } \\
\text { Konflik dalam } \\
\text { Pemanfaatan } \\
\text { SDKP } \\
\text { termasuk } \\
\text { lobster/ }\end{array}$ & $\begin{array}{l}\text { Kelembagaan } \\
\text { eksisting } \\
\text { selain } \\
\text { menjalankan } \\
\text { tupoksi nya, }\end{array}$ & & $\begin{array}{l}\text { Kelembagaan } \\
\text { eksisting } \\
\text { selain } \\
\text { menjalankan } \\
\text { tupoksi nya, }\end{array}$ & & $\begin{array}{l}\text { Kelembagaan } \\
\text { eksisting selain } \\
\text { menjalankan }\end{array}$ & & $\begin{array}{l}\text { Kelembagaan } \\
\text { eksisting tidak } \\
\text { menjalankan } \\
\text { tupoksi } \\
\text { termasuk }\end{array}$ & \\
\hline $\begin{array}{l}\text { Institutional } \\
\text { Roles \& } \\
\text { Functions in } \\
\text { Overcoming } \\
\text { Conflict in } \\
\text { Utilization of } \\
\text { Marine } \\
\text { Resources } \\
\text { Fisheries } \\
\text { including } \\
\text { lobsters }\end{array}$ & $\begin{array}{l}\text { mengatasi } \\
\text { konflik dalam } \\
\text { pemanfaatan } \\
\text { SDKP } \\
\text { termasuk } \\
\text { lobster }\end{array}$ & 3 & $\begin{array}{l}\text { mengatasi } \\
\text { konflik dalam } \\
\text { pemanfaatan } \\
\text { SDKP } \\
\text { termasuk } \\
\text { lobster }\end{array}$ & 3 & $\begin{array}{l}\text { tupoKs } \\
\text { ikut } \\
\text { konflik mengatasi } \\
\text { pemanfaatan } \\
\text { termasuk labster }\end{array}$ & 3 & $\begin{array}{l}\text { mengatasi } \\
\text { konflik } \\
\text { pemanfaatan } \\
\text { SDKP } \\
\text { termasuk } \\
\text { lobster }\end{array}$ & 1 \\
\hline
\end{tabular}

Terlihat bahwa di Kab. Pangandaran sudah ada Forum Pokmaswas yang seyogyanya juga dapat dimanfaatkan sebagai lembaga pengelola program restocking lobster. Selain itu telah dilakukan pertemuan bersama perwakilan masyarakat dan perwakilan kelembagaan yang ada dan telah disepakati perumusan kembali kepengurusan lobster menjadi Divisi Pengelolaan Program Restocking Lobster. Kepengurusan tersebut telah diusulkan pada Forum Pokmaswas dan sudah menjadi Surat 
Keputusan Bupati Kab. Pangandaran. Dalam hal ini ada Ketua dan anggota yang mewakili wilayah-wilayah penangkapan lobster di Kab. Pangandaran. Namun demikian bukan berarti wilayah lainnya tidak mendukung adanya program restocking lobster, perbedaannya hanya terletak pada tingkat kesiapan kelembagaan. Hasil yang didapatkan ini sesuai dengan hasil yang diperoleh oleh Nurfiarini et al., (2016) pada beberapa lokasi yang sama yang juga menghasilkan Kabupaten Pangandaran merupakan letak wilayah perairan yang juga sesuai secara ekologis disamping kelembagaan dan peraturan sebagaimana ditunjukkan pada Tabel 3.

Tabel 2. Hasil skoring indikator kelembagaan terkait kelompok nelayan dalam mendukung pengelolaan program restocking lobster di Indonesia.

Table 2. Scoring result of institutional indicators related to fishermen groups in supporting the management of lobster restocking program in Indonesia.

\begin{tabular}{|c|c|c|c|c|c|c|c|c|}
\hline \multicolumn{9}{|c|}{ Unsur Penilaian Kelembaqaan \& Peraturan/Institutional \& Reaulatory Assessment Elements } \\
\hline \multirow{2}{*}{$\begin{array}{l}\text { Unsur Penilaia } \\
\text { Kelompok } \\
\text { Nelayan/ } \\
\text { groups } \\
\text { fishermen }\end{array}$} & $\begin{array}{l}\text { Ian Kelembagaan } \\
\text { NTB }\end{array}$ & \multirow[b]{2}{*}{ Skol } & \multirow[b]{2}{*}{$\begin{array}{l}\text { Lombok } \\
\text { Timur }\end{array}$} & \multirow[b]{2}{*}{ Skor } & \multicolumn{2}{|c|}{ Jawa Barat } & \multicolumn{2}{|c|}{ Banten } \\
\hline & $\begin{array}{l}\text { Lombok } \\
\text { Tengah }\end{array}$ & & & & Pangandaran & Skor & Pandeglang & Skor \\
\hline $\begin{array}{l}\text { Stratifikasi } \\
\text { Sosial/ Social } \\
\text { Stratification }\end{array}$ & $\begin{array}{l}\text { Semua orang } \\
\text { dapat } \\
\text { memanfaatkan } \\
\text { dan mengelola } \\
\text { SDKP } \\
\text { termasuk } \\
\text { lobster }\end{array}$ & 3 & $\begin{array}{l}\text { Semua orang } \\
\text { dapat } \\
\text { memanfaatkan } \\
\text { dan mengelola } \\
\text { SDKP } \\
\text { termasuk } \\
\text { lobster }\end{array}$ & 3 & $\begin{array}{l}\text { Semua orang } \\
\text { dapat } \\
\text { memanfaatka } \\
\mathrm{n} \text { dan } \\
\text { mengelola } \\
\text { SDKP } \\
\text { termasuk } \\
\text { lobster } \\
\text { Pola }\end{array}$ & 3 & $\begin{array}{l}\text { biasanya } \\
\text { nelayan } \\
\text { pemanfaat } \\
\text { SDKP } \\
\text { merupakan } \\
\text { 'binaan' dari } \\
\text { pemberi modal }\end{array}$ & 1 \\
\hline $\begin{array}{l}\text { Pola hubungan } \\
\text { kerja dalam } \\
\text { pemanfaatan } \\
\text { lobster/ Pattern } \\
\text { of working } \\
\text { relationships in } \\
\text { the utilization } \\
\text { of lobsters }\end{array}$ & $\begin{array}{l}\text { Pola Hubungan } \\
\text { kerja dalam } \\
\text { pemanfaatan } \\
\text { lobster tidak } \\
\text { n berdasarkan } \\
\text { sistem } \\
\text { n kekerabatan } \\
\text { dan hubungan } \\
\text { ekonomi (Cash } \\
\text { and Carry) }\end{array}$ & 3 & $\begin{array}{l}\text { Pola Hubungan } \\
\text { kerja dalam } \\
\text { pemanfaatan } \\
\text { lobster tidak } \\
\text { berdasarkan } \\
\text { sistem } \\
\text { kekerabatan } \\
\text { dan hubungan } \\
\text { ekonomi (Cash } \\
\text { and Carry) }\end{array}$ & 3 & $\begin{array}{l}\text { Hubungan } \\
\text { kerja dalam } \\
\text { pemanfaatan } \\
\text { lobster tidak } \\
\text { berdasarkan } \\
\text { sistem } \\
\text { kekerabatan } \\
\text { dan hubungan } \\
\text { ekonomi } \\
\text { (Cash and } \\
\text { Carry) }\end{array}$ & 3 & $\begin{array}{l}\text { Pola } \\
\text { Hubungan } \\
\text { kerja dalam } \\
\text { pemanfaatan } \\
\text { lobster } \\
\text { berdasarkan } \\
\text { sistem } \\
\text { kekerabatan } \\
\text { dan hubungan } \\
\text { ekonomi }\end{array}$ & 2 \\
\hline $\begin{array}{l}\text { Organisasi } \\
\text { kemasyarakata } \\
\text { n terkait } \\
\text { masyarakat } \\
\text { nelayan/ } \\
\text { Community } \\
\text { organizations } \\
\text { related to } \\
\text { fishing } \\
\text { communities }\end{array}$ & $\begin{array}{l}\text { terbentuknya } \\
\text { sedikit jaringan } \\
\text { sosial dalam } \\
\text { masyarakat } \\
\text { akan } \\
\text { mengakibatkan } \\
\text { masyarakat } \\
\text { semakin rentan } \\
\text { terhadap } \\
\text { masalah- } \\
\text { masalah yang } \\
\text { mereka hadapi }\end{array}$ & 2 & $\begin{array}{l}\text { terbentuknya } \\
\text { sedikit jaringan } \\
\text { sosial dalam } \\
\text { masyarakat } \\
\text { akan } \\
\text { mengakibatkan } \\
\text { masyarakat } \\
\text { semakin rentan } \\
\text { terhadap } \\
\text { masalah- } \\
\text { masalah yang } \\
\text { mereka hadapi }\end{array}$ & 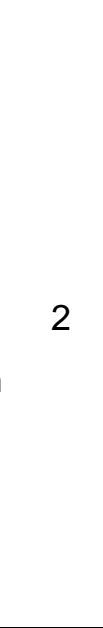 & $\begin{array}{l}\text { terbentuknya } \\
\text { jaringan sosial } \\
\text { dalam } \\
\text { masyarakat } \\
\text { akan } \\
\text { memperkuat } \\
\text { ketahanan } \\
\text { masyarakat } \\
\text { dalam } \\
\text { menghadapi } \\
\text { masalah- } \\
\text { masalah yang } \\
\text { mereka } \\
\text { hadapi }\end{array}$ & 3 & $\begin{array}{l}\text { tidak } \\
\text { terbentuknya } \\
\text { jaringan sosial } \\
\text { dalam } \\
\text { masyarakat } \\
\text { akan } \\
\text { mengakibatka } \\
\text { n masyarakat } \\
\text { sangat rentan } \\
\text { dalam } \\
\text { menghadapi } \\
\text { masalah- } \\
\text { masalah yang } \\
\text { mereka } \\
\text { hadapi }\end{array}$ & 1 \\
\hline
\end{tabular}




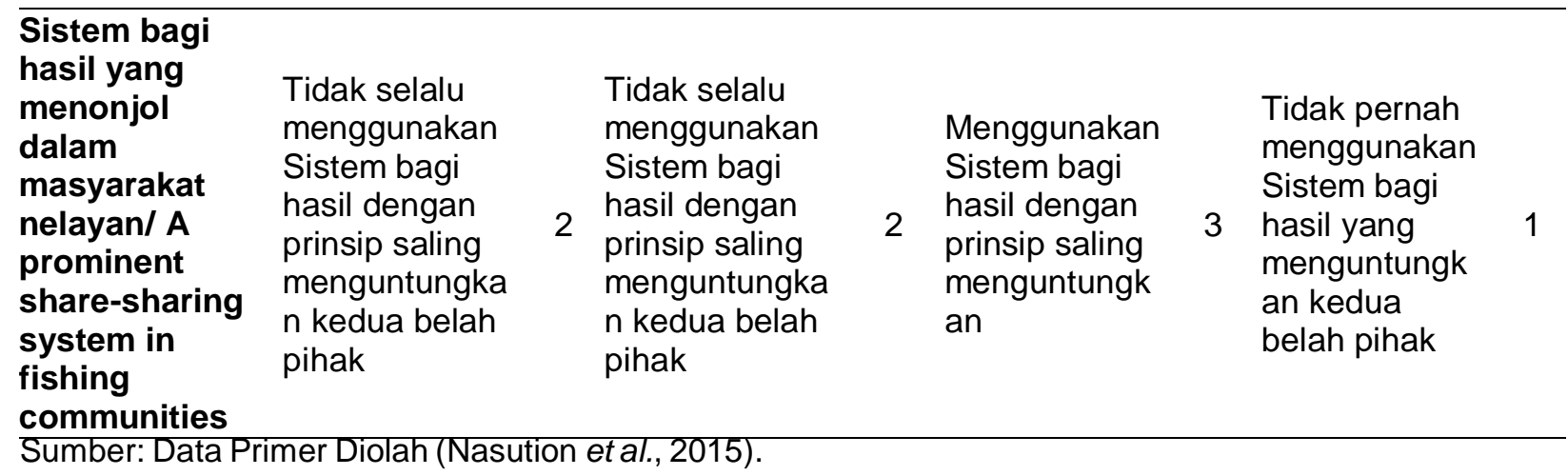

Tabel 2 juga menunjukkan bahwa di wilayah Kabupaten Pangandaran telah didukung dengan keberadaan kelompok nelayan yang memiliki pola hubungan kerja dalam pemanfaatan lobster tidak berdasarkan sistem kekerabatan dan hubungan ekonomi. Kemudian, pada masyarakat nelayan telah terbentuk jaringan sosial dalam masyarakat tersebut sehingga akan memperkuat ketahanan masyarakat dalam menghadapi masalah-masalah yang mereka hadapi. Sistem bagi hasil yang diterapkan masyarakatnya juga sebagian besar pada prinsipnya saling menguntungkan.

Tabel 3. Hasil skoring indikator kelembagaan terkait dengan peraturan pengelolaan dalam mendukung pengelolaan program restocking lobster di Indonesia.

Table 3. The results of scoring institutional indicators related to management regulations in support of the management of lobster restocking program in Indonesia.

\begin{tabular}{|c|c|c|c|c|c|c|c|c|}
\hline $\begin{array}{l}\text { Unsur Penilaia } \\
\text { Peraturan }\end{array}$ & $\begin{array}{l}\text { an Kelembagaa } \\
\text { NTB }\end{array}$ & an \& P & Peraturan / Instit & tution & $\begin{array}{l}\text { nal \& Regulatory } \\
\text { Jawa Barat }\end{array}$ & y Ass & $\begin{array}{l}\text { Bessment Eleme } \\
\text { Banten }\end{array}$ & ents \\
\hline $\begin{array}{l}\text { Pengelolaan/ } \\
\text { Management } \\
\text { Regulations }\end{array}$ & $\begin{array}{l}\text { Lombok } \\
\text { Tengah }\end{array}$ & Skor & $\begin{array}{l}\text { Lombok } \\
\text { Timur }\end{array}$ & Skor & Pangandaran & Skor & Pandeglang & Skor \\
\hline $\begin{array}{l}\text { Aturan lokal } \\
\text { terkait } \\
\text { pemanfaatan } \\
\text { SD Lobster/ } \\
\text { Local rules } \\
\text { regarding the } \\
\text { utilization of } \\
\text { Lobster } \\
\text { Resources }\end{array}$ & $\begin{array}{l}\text { Terdapat } \\
\text { aturan lokal } \\
\text { sangat terkait } \\
\text { dengan } \\
\text { pemanfaatan } \\
\text { sumberdaya } \\
\text { lobster }\end{array}$ & 3 & $\begin{array}{l}\text { Terdapat } \\
\text { aturan lokal } \\
\text { sangat terkait } \\
\text { dengan } \\
\text { pemanfaatan } \\
\text { sumberdaya } \\
\text { lobster }\end{array}$ & 3 & $\begin{array}{l}\text { Terdapat } \\
\text { aturan lokal } \\
\text { yang terkait } \\
\text { secara tidak } \\
\text { langsung } \\
\text { terhadap } \\
\text { pemanfaatan } \\
\text { sumberdaya } \\
\text { lobster }\end{array}$ & 2 & $\begin{array}{l}\text { Tidak terdapat } \\
\text { aturan lokal } \\
\text { terkait } \\
\text { pemanfaatan } \\
\text { sumberdaya } \\
\text { lobster }\end{array}$ & 1 \\
\hline $\begin{array}{l}\text { Aturan formal } \\
\text { terkait } \\
\text { pemanfaatan } \\
\text { SD Lobster/ } \\
\text { Formal rules } \\
\text { regarding the } \\
\text { utilization of } \\
\text { Lobster } \\
\text { Resources }\end{array}$ & $\begin{array}{l}\text { Terdapat } \\
\text { aturan formal } \\
\text { sangat terkait } \\
\text { dengan } \\
\text { pemanfaatan } \\
\text { sumberdaya } \\
\text { lobster }\end{array}$ & 3 & $\begin{array}{l}\text { Terdapat } \\
\text { aturan formal } \\
\text { sangat terkait } \\
\text { dengan } \\
\text { pemanfaatan } \\
\text { sumberdaya } \\
\text { lobster }\end{array}$ & 3 & $\begin{array}{l}\text { Terdapat } \\
\text { aturan formal } \\
\text { sangat terkait } \\
\text { dengan } \\
\text { pemanfaatan } \\
\text { sumberdaya } \\
\text { lobster }\end{array}$ & 3 & $\begin{array}{l}\text { Terdapat } \\
\text { aturan formal } \\
\text { yang terkait } \\
\text { secara tidak } \\
\text { langsung } \\
\text { terhadap } \\
\text { pemanfaatan } \\
\text { sumberdaya } \\
\text { lobster }\end{array}$ & 2 \\
\hline $\begin{array}{l}\text { Pemahaman } \\
\text { Masyarakat } \\
\text { terhadap } \\
\text { organisasi dan } \\
\text { peraturan } \\
\text { melalui } \\
\text { sosialisasi/ } \\
\text { Society's } \\
\text { understanding } \\
\text { of } \\
\text { organizations } \\
\text { and } \\
\text { regulations } \\
\text { through } \\
\text { socialization }\end{array}$ & $\begin{array}{l}\text { Masyarakat } \\
\text { memahami } \\
\text { organisasi dan } \\
\text { peraturan } \\
\text { melalui proses } \\
\text { sosialisasi } \\
\text { yang dilakukan } \\
\text { oleh } \\
\text { organisasi } \\
\text { pemanfaat } \\
\text { sumberdaya } \\
\text { perikanan }\end{array}$ & 3 & $\begin{array}{l}\text { Masyarakat } \\
\text { memahami } \\
\text { organisasi dan } \\
\text { peraturan } \\
\text { melalui proses } \\
\text { sosialisasi } \\
\text { yang dilakukan } \\
\text { oleh } \\
\text { organisasi } \\
\text { pemanfaat } \\
\text { sumberdaya } \\
\text { perikanan }\end{array}$ &  & $\begin{array}{l}\text { Masyarakat } \\
\text { memahami } \\
\text { organisasi dan } \\
\text { peraturan } \\
\text { melalui proses } \\
\text { sosialisasi } \\
\text { yang dilakukan } \\
\text { oleh organisasi } \\
\text { pemanfaat } \\
\text { sumberdaya } \\
\text { perikanan }\end{array}$ & 3 & $\begin{array}{l}\text { Masyarakat } \\
\text { tidak } \\
\text { memahami } \\
\text { organisasi dan } \\
\text { peraturan } \\
\text { melalui proses } \\
\text { sosialisasi } \\
\text { yang dilakukan } \\
\text { oleh } \\
\text { organisasi } \\
\text { pemanfaat } \\
\text { sumberdaya } \\
\text { perikanan }\end{array}$ & 7) \\
\hline
\end{tabular}




\begin{tabular}{|c|c|c|c|c|c|c|c|c|}
\hline $\begin{array}{l}\text { Pemahaman } \\
\text { Masyarakat } \\
\text { terhadap } \\
\text { organisasi dan } \\
\text { peraturan } \\
\text { melalui } \\
\text { sosialisasi/ } \\
\text { Society's } \\
\text { understanding } \\
\text { of } \\
\text { organizations } \\
\text { and } \\
\text { regulations } \\
\text { through } \\
\text { socialization }\end{array}$ & $\begin{array}{l}\text { Masyarakat } \\
\text { memahami } \\
\text { organisasi dan } \\
\text { peraturan } \\
\text { melalui proses } \\
\text { sosialisasi } \\
\text { yang dilakukan } \\
\text { oleh } \\
\text { organisasi } \\
\text { pemanfaat } \\
\text { sumberdaya } \\
\text { perikanan }\end{array}$ & 3 & $\begin{array}{l}\text { Masyarakat } \\
\text { memahami } \\
\text { organisasi dan } \\
\text { peraturan } \\
\text { melalui proses } \\
\text { sosialisasi } \\
\text { yang dilakukan } \\
\text { oleh } \\
\text { organisasi } \\
\text { pemanfaat } \\
\text { sumberdaya } \\
\text { perikanan }\end{array}$ & 3 & $\begin{array}{l}\text { Masyarakat } \\
\text { memahami } \\
\text { organisasi dan } \\
\text { peraturan } \\
\text { melalui proses } \\
\text { sosialisasi } \\
\text { yang dilakukan } \\
\text { oleh organisasi } \\
\text { pemanfaat } \\
\text { sumberdaya } \\
\text { perikanan }\end{array}$ & 3 & $\begin{array}{l}\text { Masyarakat } \\
\text { tidak } \\
\text { memahami } \\
\text { organisasi dan } \\
\text { peraturan } \\
\text { melalui proses } \\
\text { sosialisasi } \\
\text { yang dilakukan } \\
\text { oleh } \\
\text { organisasi } \\
\text { pemanfaat } \\
\text { sumberdaya } \\
\text { perikanan }\end{array}$ & 1 \\
\hline $\begin{array}{l}\text { Kemampuan } \\
\text { Masyarakat } \\
\text { dalam } \\
\text { melaksanakan } \\
\text { aturan / The } \\
\text { ability of the } \\
\text { community in } \\
\text { implementing } \\
\text { the rules }\end{array}$ & $\begin{array}{l}\text { Masyarakat } \\
\text { melaksanakan } \\
\text { aturan yang } \\
\text { telah dibuat } \\
\text { oleh } \\
\text { organisasi } \\
\text { pemanfaat } \\
\text { sumberdaya } \\
\text { perikanan }\end{array}$ & 3 & $\begin{array}{l}\text { Masyarakat } \\
\text { melaksanakan } \\
\text { aturan yang } \\
\text { telah dibuat } \\
\text { oleh } \\
\text { organisasi } \\
\text { pemanfaat } \\
\text { sumberdaya } \\
\text { perikanan }\end{array}$ & 3 & $\begin{array}{l}\text { Masyarakat } \\
\text { melaksanakan } \\
\text { aturan yang } \\
\text { telah dibuat } \\
\text { oleh organisasi } \\
\text { pemanfaat } \\
\text { sumberdaya } \\
\text { perikanan }\end{array}$ & 3 & $\begin{array}{l}\text { Masyarakat } \\
\text { tidak selalu } \\
\text { melaksanakan } \\
\text { aturan yang } \\
\text { telah dibuat } \\
\text { oleh } \\
\text { organisasi } \\
\text { pemanfaat } \\
\text { sumberdaya } \\
\text { perikanan }\end{array}$ & 2 \\
\hline
\end{tabular}

Sumber: Data Primer Diolah (Nasution et al., 2015).

Tabel 4. Hasil skoring indikator kelembagaan terkait peluang pelaksanaan monitoring dalam mendukung pengelolaan program restocking lobster di Indonesia.

Table 4. Scoring of institutional indicators related to monitoring opportunities in support of lobster restocking program management in Indonesia.

\begin{tabular}{|c|c|c|c|c|c|c|c|c|}
\hline \multicolumn{9}{|c|}{ Unsur Penilaian Kelembagaan \& Peraturan } \\
\hline Peluang & NTB & & & & Jawa Barat & & Banten & \\
\hline & $\begin{array}{l}\text { Lombok } \\
\text { Tengah }\end{array}$ & Skor & $\begin{array}{l}\text { Lombok } \\
\text { Timur }\end{array}$ & Skor & Pangandaran & Skor & Pandeglang & Skor \\
\hline $\begin{array}{l}\text { Keberlanjutan } \\
\text { kelembagaan } \\
\text { sesuai } \\
\text { fungsinya/ } \\
\text { Institutional } \\
\text { sustainability } \\
\text { according to } \\
\text { function }\end{array}$ & $\begin{array}{l}\text { Kelembagaan } \\
\text { yang ada } \\
\text { sudah sesuai } \\
\text { dengan tugas } \\
\text { pokok dan } \\
\text { fungsinya } \\
\text { (struktur } \\
\text { organisasi } \\
\text { jelas, aturan } \\
\text { tertulis, } \\
\text { wilayah } \\
\text { pengaturan } \\
\text { jelas, } \\
\text { mekanisme } \\
\text { pengambilan } \\
\text { keputusan, } \\
\text { monitoring dan } \\
\text { evaluasi } \\
\text { sudah berjalan } \\
\text { dengan baik) }\end{array}$ & 3 & $\begin{array}{l}\text { Kelembagaan } \\
\text { yang ada } \\
\text { sudah sesuai } \\
\text { dengan tugas } \\
\text { pokok dan } \\
\text { fungsinya } \\
\text { (struktur } \\
\text { organisasi } \\
\text { jelas, aturan } \\
\text { tertulis, } \\
\text { wilayah } \\
\text { pengaturan } \\
\text { jelas, } \\
\text { mekanisme } \\
\text { pengambilan } \\
\text { keputusan, } \\
\text { monitoring dan } \\
\text { evaluasi } \\
\text { sudah berjalan } \\
\text { dengan baik) }\end{array}$ & 3 & $\begin{array}{l}\text { Kelembagaan } \\
\text { yang ada sudah } \\
\text { sesuai dengan } \\
\text { tugas pokok } \\
\text { dan fungsinya } \\
\text { (struktur } \\
\text { organisasi } \\
\text { jelas, aturan } \\
\text { tertulis, wilayah } \\
\text { pengaturan } \\
\text { jelas, } \\
\text { mekanisme } \\
\text { pengambilan } \\
\text { keputusan, } \\
\text { monitoring dan } \\
\text { evaluasi sudah } \\
\text { berjalan } \\
\text { dengan baik) }\end{array}$ & 3 & $\begin{array}{l}\text { Kelembagaan } \\
\text { yang ada } \\
\text { kurang sesuai } \\
\text { dengan tugas } \\
\text { pokok dan } \\
\text { fungsinya } \\
\text { (struktur } \\
\text { organisasi } \\
\text { jelas, aturan } \\
\text { belum tertulis, } \\
\text { wilayah } \\
\text { pengaturan, } \\
\text { mekanisme } \\
\text { pengambilan } \\
\text { keputusan, } \\
\text { monitoring dan } \\
\text { evaluasi belum } \\
\text { berjalan } \\
\text { dengan baik) }\end{array}$ & 2 \\
\hline
\end{tabular}




\begin{tabular}{|c|c|c|c|c|c|c|c|c|}
\hline $\begin{array}{l}\text { Ketersediaan } \\
\text { sumber } \\
\text { penghasilan } \\
\text { masyarakat } \\
\text { secara } \\
\text { berkelanjutan/ } \\
\text { Availability of } \\
\text { sustainable } \\
\text { community } \\
\text { income } \\
\text { sources }\end{array}$ & $\begin{array}{l}\text { Presentase } \\
\text { pendapatan } \\
\text { masyarakat } \\
\text { yang berasal } \\
\text { dari lobster > } \\
\text { pendapatan } \\
\text { dari sektor } \\
\text { perikanan } \\
\text { lainnya }\end{array}$ & 3 & $\begin{array}{l}\text { Presentase } \\
\text { pendapatan } \\
\text { masyarakat } \\
\text { yang berasal } \\
\text { dari lobster > } \\
\text { pendapatan } \\
\text { dari sektor } \\
\text { perikanan } \\
\text { lainnya }\end{array}$ & 3 & $\begin{array}{l}\text { Presentase } \\
\text { pendapatan } \\
\text { masyarakat } \\
\text { yang berasal } \\
\text { dari lobster = } \\
\text { pendapatan } \\
\text { dari sektor } \\
\text { perikanan } \\
\text { lainnya }\end{array}$ & 2 & $\begin{array}{l}\text { Presentase } \\
\text { pendapatan } \\
\text { masyarakat } \\
\text { yang berasal } \\
\text { dari lobster > } \\
\text { pendapatan } \\
\text { dari sektor } \\
\text { perikanan } \\
\text { lainnya }\end{array}$ & 3 \\
\hline $\begin{array}{l}\text { Jumlah } \\
\text { Skoring/ Total } \\
\text { Scoring }\end{array}$ & $\begin{array}{l}\text { Lombok } \\
\text { Tengah }\end{array}$ & 45 & $\begin{array}{l}\text { Lombok } \\
\text { Timur }\end{array}$ & 45 & Pangandaran & 46 & Pandeglang & 24 \\
\hline
\end{tabular}

\section{PENGUATAN KELEMBAGAAN MASYARAKAT}

Penguatan kelembagaan yang sesuai dengan prinsip bahwa suatu program agar berkelanjutan memerlukan kelembagaan pengelola yang kondusif sehingga program tersebut dapat menjadi bagian dari kehidupan masyarakat (Soekanto, 2003). Pengembangan kapasitas kelembagaan atau penguatan kelembagaan (institutional development) diartikan sebagai pembinaan kelembagaan; dan didefinisikan sebagai proses untuk memperbaiki kemampuan lembaga guna mengefektifkan penggunaan sumberdaya manusia dan sumber daya lainnya yang tersedia. Pengembangan kelembagaan dapat meningkatkan pertumbuhan ekonomi sepanjang dalam fungsinya memungkinkan adanya pembagian kerja secara seimbang, peningkatan pendapatan, perluasan usaha dan kebebasan untuk memperoleh peluang ekonomi.

Suatu kelembagaan yang baru dibentuk perlu ditingkatkan dan atau dikembangkan kapasitasnya agar dapat berfungsi sesuai dengan tujuan yang ingin dicapai kelembagaan tersebut. Hal ini didasarkan pertimbangan bahwa suatu kelembagaan (dalam hal ini organisasi) adalah suatu entitas yang dinamis di dalam dunia yang selalu berubah, yang dari waktu ke waktu selalu berusaha untuk memenuhi misinya melalui program serta tujuan jangka pendek, menengah dan panjang. Bahkan dengan adanya beragam pengaruh lingkungan, baik dari dalam maupun dari luar, seorang pimpinan organisasi dihadapkan pada tantangan yang terus meningkat agar dapat beradaptasi terhadap perubahan yang terus-menerus berlangsung tanpa harus kehilangan arah dalam memenuhi misi organisasinya.

Pada prinsipnya peningkatan kapasitas kelembagaan dapat berupa upaya yang dilakukan pada tingkatan individu (individual level), pata tingkat organisasi (organizational level), dan pada tingkatan sistem (system level) (Milen, 2006). Pada tingkatan individu, pengembangan yang dilakukan dapat berupa pengetahuan (knowledge), keterampilan (skills), kompetensi (competencies), dan etika kerja (works ethics). Pada tingkat organisasi dapat berupa hal-hal yang terkait dengan pengambilan keputusan (decision making), sumberdaya (resources), prosedur, struktur, pengelolaan sistem informasi, dan budaya. Pada tingkatan sistem dapat berupa pengembangan legal framework dan supporting policies.

Berdasarkan kesiapan kelembagaan yang terbentuk, maka opsi kebijakan yang diperlukan agar kelembagaan yang dibentuk atau dikembangkan dapat berfungsi sebagai pengelola program restocking lobster adalah perlunya peningkatan kapasitas pengurus organisasi yang terbentuk baik terhadap program restocking lobster dan manfaatnya bagi masyarakat, sumber daya dan pemerintah pada setiap lokasi, meskipun tingkatan keperluan disesuaikan dengan kebutuhan masing-masing lokasi. Dalam hal ini pemahaman yang benar terhadap program akan menghasilkan pola pengelolaan yang berkelanjutan. Termasuk didalamnya diperlukan kebijakan sistem produksi tentang pembatasan upaya penangkapan ikan terutama kaitannya dengan penggunaan alat tangkap yang mengakibatkan terganggunya siklus hidup lobster. Terganggunya siklus hidup ikan/lobster dapat mengakibatkan terjadinya penurunan populasi lobster secara drastis. Kemudian, perlu pembatasan penggunaan alat tangkap yang saat ini menggunakan umpan dan menggunakan mata jaring yang berukuran kurang dari $1 \mathrm{~cm}$, yang dapat menangkap hampir keseluruhan jenis dan ukuran obster. Selain itu, juga diperlukan dukungan sarana dan prasarana yang memberikan kelancaran terutama dalam bertugas sebagai pengawasan lapangan terhadap para petugas yang ditetapkan. 
Perlu pula penyempurnaan kebijakan terkait dengan upaya penguatan kelembagaan dalam bentuk penguatan aturan yang terkait dengan keperluan pengelolaan sumberdaya lobster, sehingga dapat mendukung keberlanjutan keberadaan populasi ikan pada masa kini dan masa mendatang. Dalam hal ini perlu dilakukan pembuatan aturan penangkapan, konservasi sumber daya, dan pengawasan, yang kesemuanya perlu disepakati oleh masyarakat pengguna atau stakeholder terkait. Dalam hal ini seyogyanya telah disepakati terlebih dahulu mekanisne yang diberlakukan terkait dengan otoritas penegakan aturan beserta sanksi yang diberikan kepada pelanggar aturan.

Penyempurnaan kebijakan terkait peluang investasi dan kebijakan yang diperlukan terkait dengan program peningkatan produksi ikan/lobster dan peluangpeluang investasi yang ditimbulkan sebagai akibat adanya program tersebut. Dalam hal ini, misalnya terbukanya upaya pengembangan budidaya untuk beberapa komoditas tertentu, termasuk lobster.

\section{KESIMPULAN DAN REKOMENDASI Kesimpulan}

Hasil penilaian kondisi faktor-faktor penyusun indikator kelembagaan masyarakat dalam pengelolaan program restocking lobster pada wilayah Kabupaten Lombok Timur, Lombok Tengah, Pangandaran dan Pandeglang menemukan bahwa lokasi yang paling memiliki kesiapan dalam mendukung program restocking adalah Kabupaten Pangandaran. Hal ini tercermin dari kesiapan kelembagaan pengelolaan sumberdaya perikanan beserta Lembaga POKMASWAS yang sudah memiliki fungsi dan peran dalam pemanfaatan dan pengelolaan sumberdaya perikanan (termasuk lobster).

\section{Rekomendasi}

Berdasarkan kesiapan kelembagaan yang terbentuk, maka opsi kebijakan yang diperlukan adalah peningkatan kapasitas pengurus organisasi yang terbentuk, baik terhadap program restocking lobster dan manfaatnya bagi masyarakat, sumber daya dan pemerintah. Dalam hal ini perlu dilakukan pembuatan aturan penangkapan, konservasi sumber daya,dan pengawasan, yang kesemuanya perlu disepakati oleh masyarakat pengguna atau stakeholder terkait. Disamping itu, juga kebijakan terkait peluang investasi dan kebijakan yang diperlukan terkait dengan program peningkatan produksi lobster.

\section{PERSANTUNAN}

Terima kasih kepada: Kepala Pusat Penelitian Sosial Ekonomi Kelautan dan Perikanan yang memberi kepercayaan pada penulis untuk mengkaji aspek sosial dan kelembagaan perikanan lobster pada tahun 2015. Terima kasih juga kepada petugas Dinas Kelautan dan Perikanan di Kabupaten Lombok Tengah dan Lombok Timur, Kabupaten Pangandaran dan Kabupaten Pandeglang yang telah membantu dalam penyediaan dan memperlancar pengumpulan data lapangan kegiatan ini. Begitu pula kepada para pedagang dan nelayan informan dalam kegiatan pengumpulan data primer di lapangan, kami ucapkan terimakasih yang sebesar-besarnya. Karya tulis ini merupakan bagian dari laporan kegiatan Pusat Penelitian Sosial Ekonomi Kelautan dan Perikanan dengan dana APBN-P tahun 2015.

\section{DAFTAR PUSTAKA}

Aisyah, B. \& Triharyuni, S. (2009). Lobster Seed Resources in the South Coast of Yogyakarta. p.25. AARD MMAF (Unpublished Report, in Indonesian with English Abstract).

Braun, J. V. \& Feldbrudge, T. (1998). Institutional Aspects of the Handling of Crises and Disasters in Developing Countries. Institute for Scientific Cooperation. Tubingen. Federal Republic of Germany. ECONOMICS. Vol. 57. pp. 95-113.

DJPB (Direktorat Jenderal Perikanan Budaya). (2003). Pengelolaan Perikanan Berbasis Budidaya (Culture Based Fisheries). Hotel Grasia, Semarang. Jawa Tengah. p.9. Makalah disampaikan pada Workshop Culture Based Fisheries. Tanggal 2-4 Juni 2003.

Dye, T. R. (2005). Understanding Public Policy. p.356. Prentince-Hall Inc.

Fauzi, M., Prasetyo, A.P., Hargiyatno, I.T., Satria, F. \& Ansri. A. (2013). Hubungan Panjang-Berat dan Faktor Kondisi Lobster Batu (Panulirus penicillatus) di Perairan Selatan Gunung Kidul dan Pacitan. BAWAL Vol 5 (2). Agustus 2013: 97-102.

Hargiyatno, I.T., Satria, F, Prasetyo, A.P. \& Fauzi, M. (2013). Hubungan Panjang-Berat dan Faktor Kondisi Lobster Pasir (Panulirus homarus) di Perairan Selatan Gunung Kidul dan Pacitan. BAWAL Vol 5 (1). April 2013: 41-48. 
Israel, A. (1987). Institutional Development: Incentive to Performance. The Johns Hopkins University Press. Baltimore and London.

KKP (2015a). Peraturan Menteri Kelautan dan Perikanan No.1/Permen KP/2015. Tanggal 6 Januari 2015. Tentang Penangkapan Lobster (Panulirus spp.), Kepiting (Scylla spp.), dan Rajungan (Portunus pelagicus spp.). Kementerian Kelautan dan Perikanan. Berita Negara Republik Indonesia Tahun 2015 Nomor 7.

KKP (2015b). Surat Edaran Menteri Kelautan dan Perikanan No.18/Men KP/2015 tanggal 20 Januari 2015. Tentang Penangkapan Lobster (Panulirus spp.), Kepiting (Scylla spp.), dan Rajungan (Portunus spp.). Kementerian Kelautan dan Perikanan.

Koentjaraningrat (1997). Kebudayaan Mentalitas dan Pembangunan. Jakarta. Gramedia Pustaka Utama.

Kolopaking, L. (1998). Pengembangan Kelembagaan. Departemen Komunikasi Pengembangan Masyarakat (KPM). Bogor. Fakultas Ekologi Manusia. Institut Pertanian Bogor.

Mallawa, A. (2006). Pengelolaan Sumberdaya Ikan Berkelanjutan dan Berbasis Masyarakat. Disajikan pada Lokakarya Agenda Penelitian Program COREMAP II Kab. Selayar, 9-10 September 2006. p.31. Diunduh di http://regional.coremap.or.id/ downloads/Materi-pengelolaan.pdf pada tanggal 22 Februari 2015.

Marshall, C \& Rossman, G. B, (1989). Designing Qualitative Research, London. Sage Publications.

Martin, C.J. (1971). Planning Institutions: In. M.G.Blase (Ed); Institutitons in Agricultural Development. p.91-105. Ames. lowa. The lowa State University Press.

Milen, A. (2006). Capacity Building: Meningkatkan Kinerja Sektor Publik. Yogyakarta. Penerbit Pembaruan.

Moleong, L. J. (2004). Metodologi Penelitian Kualitatif. Edisi Revisi. Bandung. Penerbit CV Remadja Rosdakarya.

Nasution, Z. (2000). Analisis Kelembagaan dan Perilaku Petani Ikan Dalam Pengelolaan Lingkungan Perairan (Studi Kasus di Perairan Waduk Jatiluhur, Jawa Barat). Bogor. Program Pascasarjana. Institut Pertanian Bogor.

Nasution, Z. (2012). Kelembagaan Pengelolaan Sumberdaya Perikanan "Lelang Lebak Lebung" dan Kemiskinan Masyarakat Nelayan (Studi Kasus di Kabupaten Ogan Komering Ilir - Sumatera Selatan). Bogor. Disertasi. Sekolah Pascasarjana, Institut Pertanian Bogor.

Nasution, Z. (2013). Pengembangan Kelembagaan Nelayan dalam Pengelolaan Perikanan Perairan Umum Daratan. Orasi Pengukuhan Profesor Riset Bidang Sosial Ekonomi Kelautan dan Perikanan. Jakarta. Kementerian Kelautan dan Perikanan. Badan Penelitian dan Pengembangan Kelautan dan Perikanan.

Nasution, Z, Zulham, A. Manadiyanto, Erlina, M.D. Pranowo, S.A. Kurniasari, N. Muhartono, R. Istiana, Kurniawan, T, Bayu V. I. Yanti, Nurlaili, \& Yuliati, C. (2015). Kajian Penguatan Kelembagaan Restocking Lobster Berbasis Masyarakat. Laporan Teknis Kegiatan Penelitian. Jakarta. . Balitbang KP. Kementerian Kelautan dan Perikanan. Balai Besar Penelitian Sosial Ekonomi Kelautan dan Perikanan

Nurfiarini, A., Wijaya, D. Mujiyanto, Satria, F. Kartamihardja, E,S. (2016). Pendekatan Sosial Ekologi Untuk Penilaian Kesuaian Lokasi Restocking Lobster Pasir Panulirus Homarus (Linnaeus, 1758) pada Beberapa Peraian di Indonesia. JPPI 22 (123-138). http:// ejournal.balitbang.kkp.go.id/index.php/jppi

Patton, M. Q. (2006). Metode Evaluasi Kualitatif. (Terjemahan Budi Puspo Priyadi). Yogyakarta. Pustaka Pelajar.

Schmid, A.A. (1972). Analytical Institutional Economics: Challenging Problems in the Economics of Resources for a New Environment. American Agricultural Economics Association. American Journal of Agricultural Economics. Vol. 54 No. 5. p.893-909.

Setyono, D.E.D. (2006). Budidaya Pembesaran Udang Karang (Panulirus spp). Oseana, 31 (4): 39-48.

Soekanto, S. (2003). Sosiologi: Suatu Pengantar. Jakarta. p.466. PT. Raja Grafindo Persada.

Suastika, M., Sukadi, F. dan Surachman. A. (2008). Studi Kelayakan: Meningkatkan pembesaran dan nutrisi lobster di Nusa Tenggara Barat. ACIAR. Final Report Kegiatan Penelitian ACIAR-SADI.

Subarsono, A.G. (2006). Analisis Kebijakan Publik; Konsep, Teori dan Aplikasi; Yogyakarta. Pustaka Pelajar. 